\title{
PERCUTANEOUS ABSORPTION OF TRITIUM OXIDE
}

by

C. W. DeLong

July 90,1951

Biology Division

HEALTH INSTRUMENT DIVISIONS

B. A. Kornber , Head Biolog Division
H. M. Parker, Manager

Health Instrument Divisions

HANFORD WORKS

RICHLAND, WASHINGTON

Operated for the Atomic Energy Commission by the

General Electric Company

under

Contract w-31-109-Eng-52
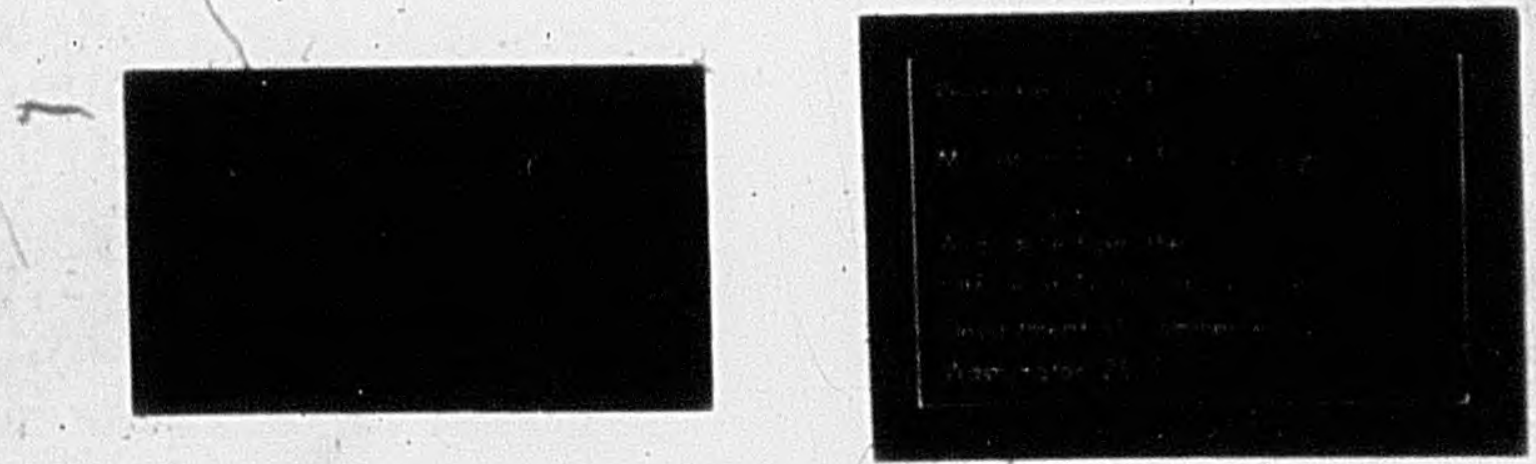


\section{SUMMARY}

Data are presented on the absorption of tritium oxide vapor through humin sidn. Under the experimental conditions used, the average rate constant was found to be $0.28 \pm 0.08 \mu \mathrm{c} / \mathrm{cm}^{2} \mathrm{kin} / \mathrm{min} \mathrm{per} \mu \mathrm{c} / \mathrm{cc}$ of etmosphere for the forearm exposures, but some of the data suggested a hifher rate constant for other portions of the body surface. The effects of various parameters on percutaneous absorption are discussed, and the relationship of the date to estimation of maximum permisatble limits is mentioned brieny.

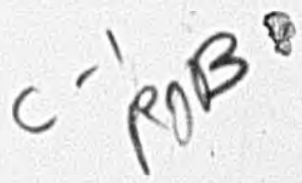




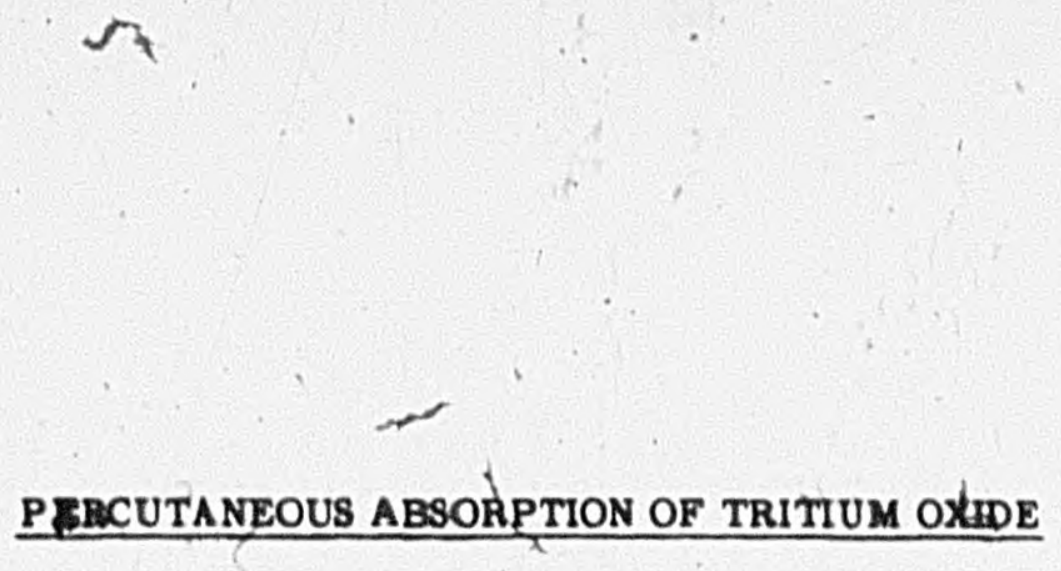

INTRODUCTION

An article by Szczesniak, et aㅐ, (3) summarizes briefly previous work reported on the percutaneous absorption of liquid water in contact with the skin. Rothman, in two extensive literature reviews covering the period from 1920-1943 $(4,5)$, concluded that water is not absorbed by mammalian skin; but Szczesniak, using deuterium oxdde as a tracer, proved conclusively that water enters the circulation through the skin of the rat.

On the basis of data from one human subject, Pinson (6) estimated the rate of percutaneous absorption of liquid water in contact with the ckln' to be $50 \times 10^{-6} \mathrm{~g} / \mathrm{cm}^{2} / \mathrm{min}$. In contrast to this, we have calculated an absorption rate of $830 \times 10^{-6} \mathrm{~g} / \mathrm{cm}^{2} / \mathrm{min}$ on the basis of data from a similar experiment on one rat.

We have chosen in the present investigation to limit ourselves to study of absorption from the vapor state because this is more nearly representative of conditions under which personnel will be exposed to 
tritium oxideja separations processes. Some of our preliminary work with rats on absorption from vapor is in process of publication (7). In this work we found that the absorption rate for rats is of the same order of magnitude as that for human subjects.

\section{METHODS}

\section{Exposure Equipment}

Exposures to vapor containing tritium oxide were accomplished in two ways. In pilot experiments a closed system was omployed, this involving a reservoir of tritium oxide water solution in a small cup inside the exposure chamber and placement of the chamber on the skin, no provision being made for active circulation of the vapor (Figure 1). The main series of exposures was made with a dynamic-type chamber which permitted passage of a stream of vapor over the skin (Figure 2). Equipment for the dynamic system consisted of a hydrator in which dried air was passed through a sintered glass filter stick into the water solution of tritium oxide, and the chamber itself in which the saturated, vapor was passed over the skin and out into a dry ice trap.

The dymamic chamber was designed to eliminate uncertainties as to the rate and degree of equilibration of liquid and gaseous water. Pepdic sampling of the chamber atmosphere was carried out for the closed ays tem experimental work, but was discontinued for the dynamic system because of the considerable difficulties involved. Atmospheric tritium oxide concentration was simply calculated on the assumption of complete saturation with water vapor under the experimental conditions employed. The temperafure of the hydrator and exposure chamber was maintained at $30^{\circ} \mathrm{C}$. $\pm 2^{\circ} \mathrm{C}$. by a warm air blower. Amblent temperature varied from $20-25^{\circ} \mathrm{C}$.

\section{Exposure Propram}

This was divided into pilot studies employing the closed system exposure chamber and a single main series of exposures employing the dyamic exposure chamber. The former included: 


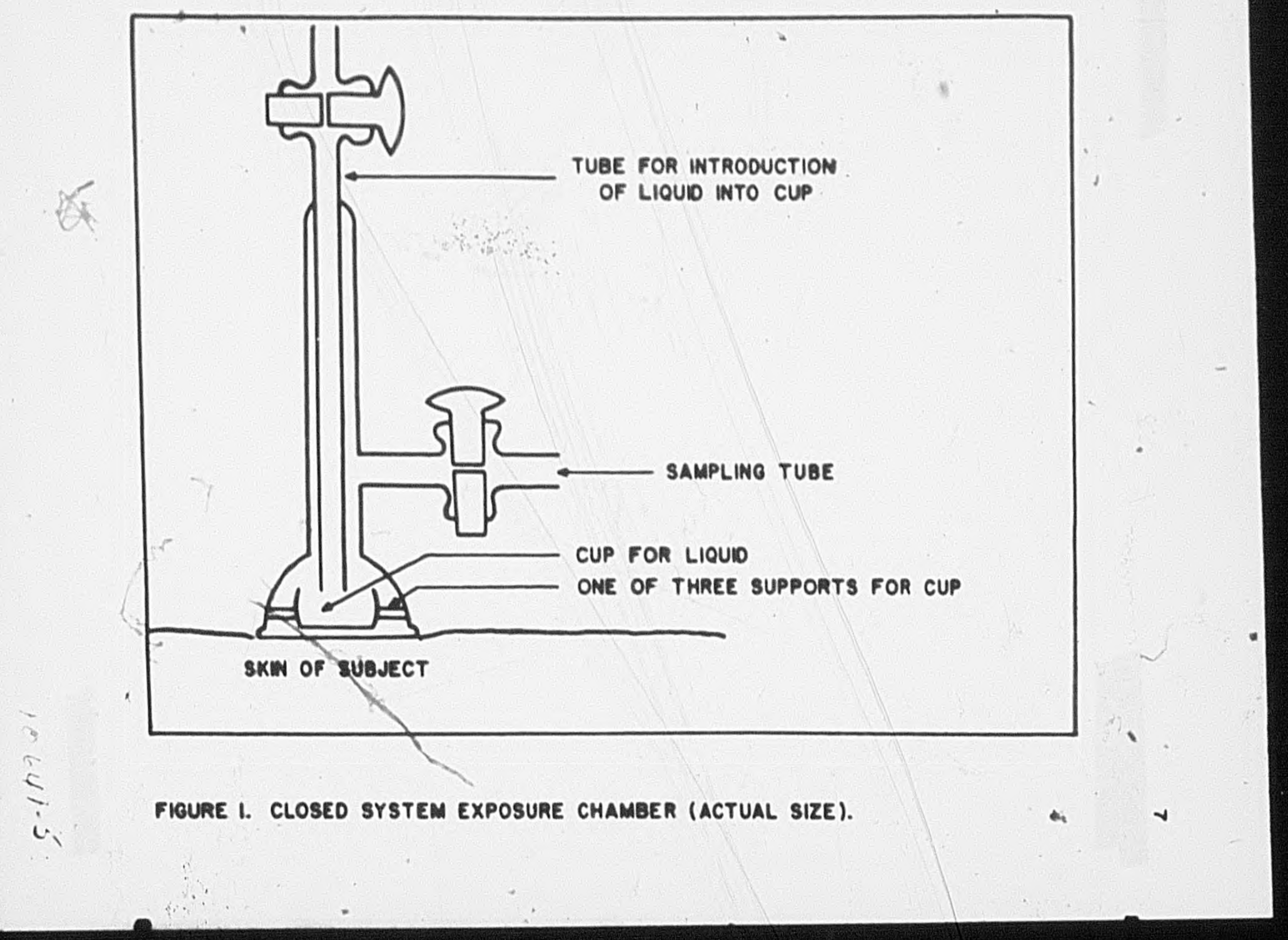




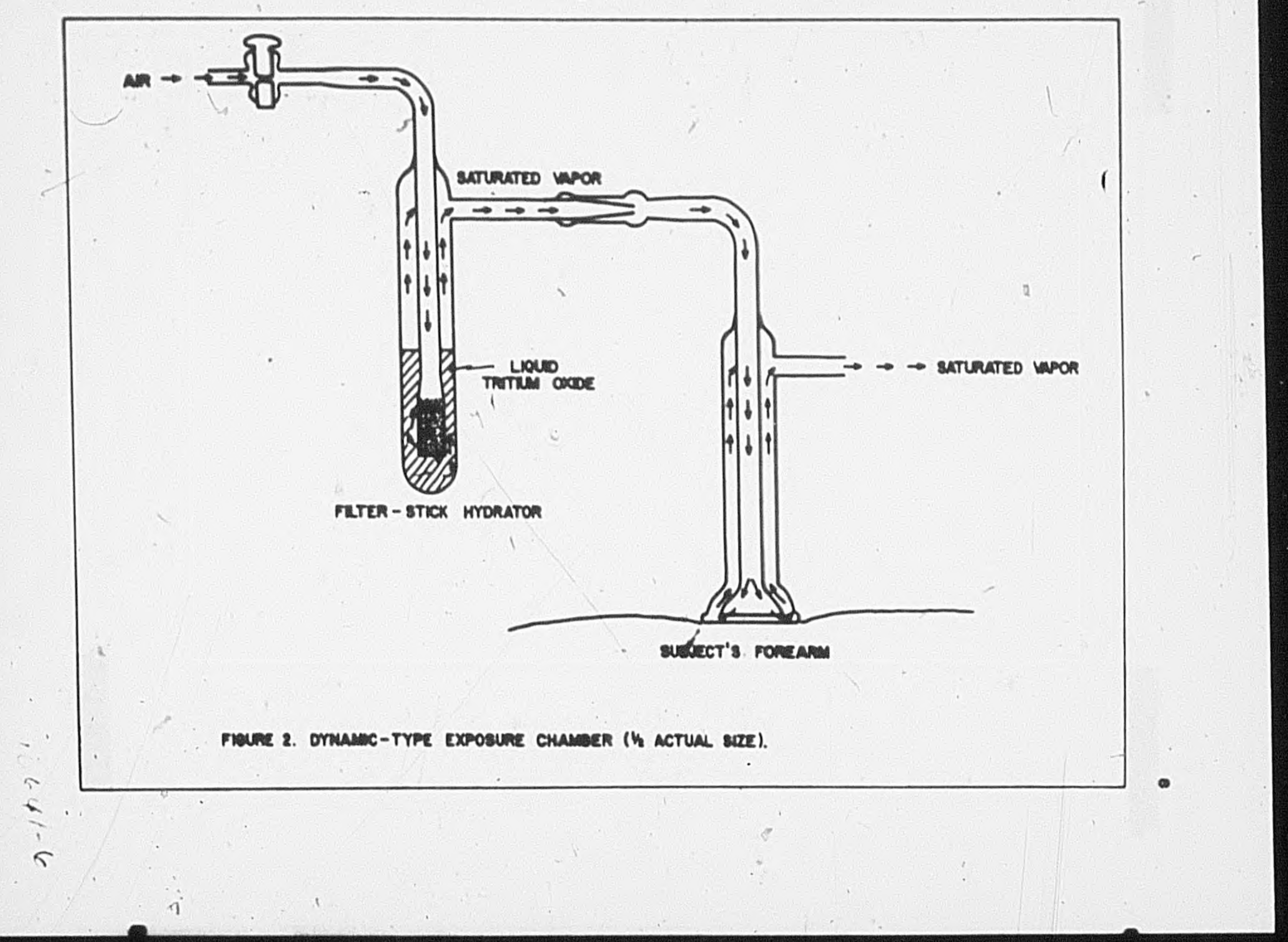


1. Low Level - $8.75 \mathrm{mc} / \mathrm{cc}$ aqueous phase or $0.26 \mu \mathrm{c} / \mathrm{cc}$ vapor phase.

Sites: upper central abdomen, Subject 1 central portion of axilla, Subject 12

2. Intermediate Level - $75 \mathrm{mc} / \mathrm{cc}$ aqueous phase or $2.3 \mu \mathrm{c} / \mathrm{cc}$ vapor phase

Sites: upper central abdomen, Subjegt 1

- dorsum of forearm, Subject 2

3. High Level $-200 \mathrm{mc} / \mathrm{cc}$ aqueous phase or $6.1_{\mu \mathrm{c}} / \mathrm{cc}$ vapor phase.

Site: upper central abdomen, Subject 3

The main series consisted of exposure of subject 12 - 12 to a level of $200 \mathrm{mc} / \mathrm{cc}$ aqueous phase or $6.1 \mu \mathrm{c} / \mathrm{cc}$ vapor phase, the site in all cases being the dorsum of the forearm.

The area exposed, $9.8 \mathrm{~cm}^{2}$, was not treated or shaved, and the exposure chamber was held in place by gentle pressure. The periods of exposure were uniformily one hour. All subjects were healthy adult males, and each was requested to maintain normal dietary and fluid intake during the sampling period. Urine sampling was chosed as the most convenient method of following tritium oxide concentration in the body fluids. In those subjects who were exposed more than once $(1,2,3)$ the later exposures were carried out only after the urinary tritium oxide level was below the detectable limit of two microcuries per liter. All pre-exposure urine samples were less than two $\mu \mathrm{c} / 1$.

\section{Analysis of Samples}

Analyses were carried out in a hydrogen counter (8), the hydrogen being generated by addition of urine samples to calcium metal with calcium chloride catalyst. Samples were also analyzed by the vibrating reed electrometer method in which urine samples are added to calcium carbide for conversion to acetylene ( 9 ).

Because two analytical methods were used, it should be pointed out that, statistically, there was no significant difference between values obtained by the two methods, nor was there a significant difference between values of samples obtained six hours after exposure and values of samples 
taken the morning after exposure (16-25 hours). The standard deviation of any individual urine sample from one subject was \pm 4.5 per cent; . hence in calculations of absorption rates the average of four values (two determinations by different methods on each of two urine samples) was used.

\section{Calculations}

The method for calculation of the absorption rate constant $(k)$ was as follows :

$$
k=\frac{U C_{i}}{A t C_{e}}
$$

$U$ - Volume orbody water (litefs)

$\mathrm{C}_{1}$ - Concentration of tritium in body water $(\mu \mathrm{c} / 1)$

A - Area of skin exposed $\left(\mathrm{cm}^{2}\right)$

$t$ - Time of exposure (min.)

$\mathrm{C}_{\mathrm{e}}$ - Concentration of tritium oxide in vapor $(\mu \mathrm{c} / \mathrm{cc})$

Thus the rate constant is in units of $\mu \mathrm{c} / \mathrm{cm}^{2} / \mathrm{min} / \mu \mathrm{c} / \mathrm{cc}$.

\section{RESULTS}

In Tables 1 and 2 are listed for each subject the body reight, body water, site of exposure, average post-exposure urine activity, and absorption rate constant. Body water is calculated, on a basis of 62 per cent of body weight, as found by Schloerb, et al (10), rather than on the basis of 71 per cent as recommended by the International Commission on Radiological Protection (II).

Results from the low level pilot study were not tabulated because the urinary tritium activity was below the detectable limit. This demonstrated that the $8.75 \mathrm{mc} / \mathrm{cc}$ aqueous phase, or $0.26 \mu \mathrm{c} / \mathrm{cc}$ vapor phase, was an insufficient concentration for tritium oxide vapor absorption studies. The intermediate level of $75 \mathrm{mc} / \mathrm{cc}$ aqueous phase, or 2.3 $\mu \mathrm{c} / \mathrm{cc}$ vapor phase, was sufficient for detection but not adequate to permit accurate analysis. Therefore a level of $200 \mathrm{mc} / \mathrm{cc}$ aqueous phase, 
TABLE 1

Pilot Studies, Intermediate and High Level

\begin{tabular}{|c|c|c|c|c|c|}
\hline $\begin{array}{c}\text { Subject } \\
\text { Code }\end{array}$ & $\begin{array}{c}\text { Body Wt. } \\
(\mathrm{kg})\end{array}$ & $\begin{array}{c}\text { Body Water } \\
\text { (liters) }\end{array}$ & $\begin{array}{c}\text { Exposure } \\
\text { Site }\end{array}$ & $\begin{array}{c}\text { Urine } \\
\text { Activity } \\
(\mu \mathrm{c} / \mathrm{l})\end{array}$ & $\begin{array}{c}\text { Absorption Rate } \\
\text { Constant }\end{array}$ \\
\hline 1 & 65.8 & 41 & Abdomen & 11 & 0.33 \\
2 & 88.5 & 55 & Forearm & 5.3 & 0.22 \\
3 & 68.0 & 42 & Abdómen & 31 & 0.37 \\
\hline
\end{tabular}

TABLE 2

High Level Study*

\begin{tabular}{|c|c|c|c|c|}
\hline $\begin{array}{c}\text { Subject } \\
\text { Code }\end{array}$ & $\begin{array}{c}\text { Body Wt. } \\
(\mathbf{k g})\end{array}$ & $\begin{array}{c}\text { Body Water } \\
(\text { liters) }\end{array}$ & $\begin{array}{c}\text { Urine } \\
\text { Activity } \\
(\mu \mathrm{c} / 1)\end{array}$ & $\begin{array}{c}\text { Absorption Rate } \\
\text { Constant }\end{array}$ \\
\hline 2 & 88.5 & 55 & 15 & 0.23 \\
3 & 68.0 & 42 & 18 & 0.21 \\
4 & 97.5 & 61 & 13 & 0.22 \\
5 & 79.4 & 49 & 19 & 0.26 \\
6 & 113.4 & 70 & 16 & 0.32 \\
7 & 80.7 & 50 & 17 & 0.23 \\
8 & 70.8 & 44 & 18 & 0.22 \\
9 & 88.5 & 55 & 30 & 0.46 \\
10 & 72.6 & 45 & 26 & 0.32 \\
11 & 78.4 & 49 & 28 & 0.39 \\
12 & 81.6 & 51 & 19 & 0.27 \\
\hline
\end{tabular}

* Site of exposure was forearm in all cases. 
or $6.1 \mu \mathrm{c} / \mathrm{cc}$ vapor phase, was chosen.as being most appropriate for producing easily detectable tritium oxide concentrations while avoiding body concentrations greater than the permissible maximum of $200 \mu \mathrm{c} / 1$ (11).

From Table I we see that subjects 1 and 3 , in whom the exposure site was the upper abdomen, exhibited an absorption rate constant of 0.33 and 0.37 respectively. Subject 2 shows a rate constant 010.22 in Table 1 and 0.23 in Table 2, the exposure site being the dorsum of the forearm in both exposures. This suggests a slightly lower rate of absorption from the latter site, and strengthening this impression is the fact that the rate constant for subject 3 was less for the dorsum of the forearm $(0.21)$ than for the upper abdomen (0.37).

The average rate constant for exposures made on dorsum of forearm is $0.28 \pm 0.08 \mu \mathrm{c} / \mathrm{cm}^{2} / \mathrm{min} / \mu \mathrm{c} / \mathrm{cc}^{\prime}$. This standard deviation of $28 \mathrm{per}$ cent is about the same as that for the urine activity average for all subjects together, 27 per cent, which indicates that including the amount of body water in the calculation for a rate constant does not aid in standardizing results. Possible reasons for variations in rate constant are considered in subsequent discussion.

\section{DISCUSSION}

The foregoing results were obtained under a single set of carefully controlled conditions. Variation in these conditions would be expected to influence the rate of percutaneous tritium oxide absorption. While the effects of such variation cannot be accurately assessed at the present time, one can make qualitative predictions as to their influence.

The effect of temperature on the absorption process has not been studied, but a large effect would not be anticipated. The effact of the partial pressure of water vapor in the atmosphere on tritium oxide absorption is one which is being currently investigated in extensive experiments on rats. Preliminary results would seem to indicate an increase in the value of the rate constant for tritium oxide absorption with decreas ing water vapor pressure. This is reasonable if one thinks of the per- 
cutaneous absorption of tritium oxide and of ordinary water vapor as being competitive processes.

For chronic exposure to an atmosphere containing tritium oxide, ordinary, permeable clothing would be expected to have no effect on percutaneous absorption. However, for momentary, sharp increases in air contamination levels, such clothing would probably offer considerable protection.

In addition to these environmental factors, a number of variables is inherent in the biological system involved. Individual variation is common to all biological processes and is difficult to assess except by extensive measurements on a large number of subjects.

The obvious differences in skin from site to site would lead one to expect some difference in absorption rates at various locations. Our data suggest that the rate of absorption from abdominal skin is nearly twice that frorn the forearm, but the paucity of tests precludes any definite conclusions.

Body water content is not strictly a function of body weight but depends upon the amount of fat present; as the amount of fat increases, the percentage of body water decreases quite rapidly (10). This would not influence the actual absorption rate, but would introduce an error in the calculation of the rate from body water activity measurements. In the present investigation, the calculated rate constahts might have been more uniform had the body water content of each subject been measured.

Skin defects, such as cuts or abrasions, definitely affect absorption. Data from rat experiments indicate that a very small wound in the exposure area increases the absórption rate by a factor of ten or more. With a large area of nearly two square meters, as in human subjects, the effect of small cuts is difficult to assess, but the absorption rate will increase if skin breaks are present.

Using the average rate constant of $0.28 \mu \mathrm{c} / \mathrm{cm}^{2} / \mathrm{min} / \mu \mathrm{c} / \mathrm{cc}$, with reservations implicit in the above discussion, the body burden of 
tritium oxide from \$kin absorption over an eight hour period can be calculated in the following manner:

$$
k A t C_{e}=(0.28)\left(1.8 \times 10^{4}\right)(480) C_{e}=2.42 \times 10^{6} C_{e}
$$

where $\mathrm{k}$ is the rate constant, $A$ is surface area of a $70 \mathrm{~kg}$ and $170 \mathrm{~cm}$ man (12), $t$ is time in minutes and $C_{e}$ is concentration of tritium oxide per cc of air. The body burden from inhalation in the same period would be $10^{7}$ $\mathrm{C}_{\mathrm{e}}$, where $10^{7}$ is the number of cc inhaled per eight hours (11). Thus the total body burden from the two sources would be $10^{7} \mathrm{C}_{e}+2.42 \times 10^{6} \mathrm{C}_{e}$ or approximately $1.25 \times 10^{7} \mathrm{C}_{\mathrm{e}^{\text {, }}}$, which means that skin absorption contributes about 20 per cent of the total. This percentage might well be considerably higher than 20 per cent, since, as indicated in the previous discussion, our experimentally determined rate constant is a conservative figure.

The significant contribution of percutaneously absorbed tritium oxide to the total body burden derived from the atmosphere would seem to be a factor worthy of consideration in the establishment of maximum permissible levels of air contamination. The currently accepted MPL of $5 \times 10^{-5} \mu \mathrm{c} / \mathrm{cc}$ (11) was based on considerations of pulmonary absorption only. Our present data are hardly sufficient to warrant any quantitative recommendation concerning recalculation of the MPL. They do suggest, however, that eventually some revision may be necessary. They also emphasize the fact that respiratory protection alone cannot be relied upon to protect a person in a highly contaminated atmosphere.

We have intentionally a voided discussion of the mechanism involved In percutaneous absorption of water. This is a more fundamental problem, not bearing directly on hazard control' research, and will require more detailed study of the phenomena. Research is being continued, including studies on percutaneous absorption of tritium gas. 


\section{ACKNOWLEDGMENTS .}

I wish to thank Drs. H. A. Kornberg, R. C. Thompson, and J. Katz for their interest and many helpful suggestions in this work. I appreciate the aid of Mr. A. C. Case and the Analyses Group of the Biology Division in the tritium analyses, and of Dr. C. A. Bennett, Statistics Group of Technical Services Division, in the statistical analysis of data.

lb 


\section{BIBLIOGRA PHY}

1. Adley, F. E., and J. M.- Smith, Jr., "Tritium Extraction Process H. I. Considerations", Document HW-11305,(1948) (SECRET).

2. Parker, H. M. , "P-10 Hazards", Document HW-15634,(1950) (SECRET).

3. Szczesniak, A.S., H. Sherman, and R. S. Harris, "The percutaneous absorption of water", Science 113,283 (1951).

4. Rothman, S., "Principles of percutaneous absorption", J. Lab. Clin. Med. 28, 1305 (1943).

5. Rothman, S., and P. Flesche, "The physiology of the skin", Ann. Rev. Physiol. 6, 195 (1944).

6. Pinson, E. A. , "The body absorption, distribution, and excretion of $₫$ ritium in man and animals", Document LA-1218, (1851) (OFFICIAL USE ONLY).

7. DeLong, C. W., "The percutaneous absorption of water vapor", Science, in press.

8. Keohmstedt, P. L., L. C. Schwendiman, J. W. Healy, Report on a hydrogen counter for analysis of tritium. (In process of prepara tion).

9. Thorburn, R. C. , "Health monitoring of samples for P-10 oxide", Document HW-17257,(1950) (SECRET).

10. Schloerb, P. R., B. J. Friis-Hansen, I. S. Edelman, A. K. Solomon, and F. D. Moore, "Measurement of total body water in the human subject by deuterium oxide dilution, with consideration of the dynamics of deuterium distribution", J. Clin. Invest. 28, 1296 (1950).

11. International Commission on Radiological Protection, "International Recommendations on Radiological Protection", revised at the Sixth International Congress of Radiology, London, July 1950, Radiolopy 56, 431 (1951).

12. Best, C. H. , and N. B. Taylor, "The Physiological Basis of Medical Practice", The Williams and Wilkins Company, Baltimore, 1943, pp. $896-7$.

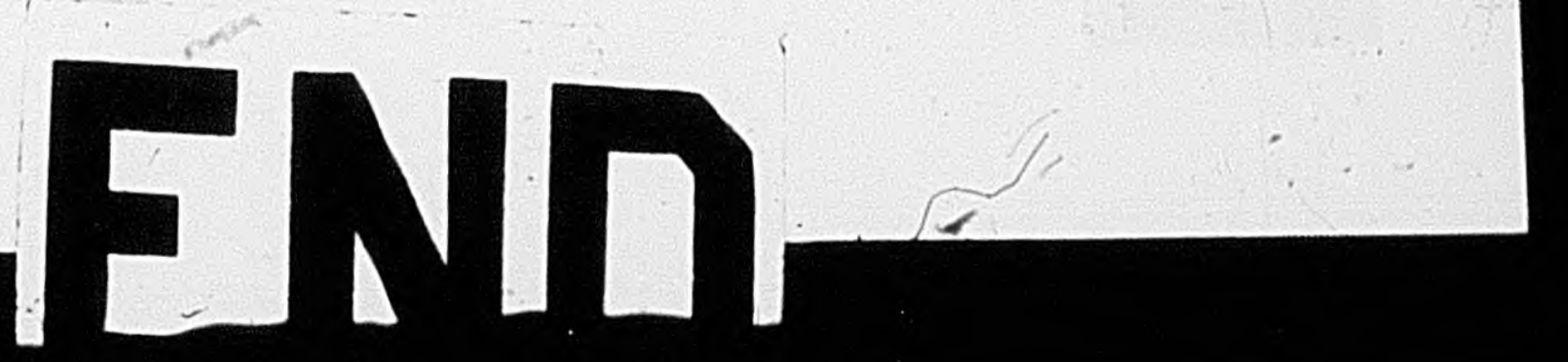

